\title{
Does Metformin Assist New Anti-Diabetic Drugs to Succeed?
}

\author{
Hisayuki Kastuyama ${ }^{\text {a }}$, Hidekatsu Yanai ${ }^{a}$ b
}

\section{To the Editor}

Metformin is the most widely used oral anti-diabetic drug and is currently recommended as first line therapy for all newly diagnosed type 2 diabetes [1]. Metformin-induced activation of the energy-sensor adenosine monophosphate (AMP)-activated protein kinase (AMPK) is well documented [2]. Metformin inhibits the complex 1 of the mitochondrial electron chain, which induces a drop in cellular energy charge [3, 4]. Reduced cellular adenosine triphosphate (ATP) concentration and an increase in both adenosine diphosphate (ADP)/ATP and AMP/ ATP ratios activates the AMPK, a critical energy sensor of cellular energy homeostasis that integrates multiple signaling networks to coordinate a wide array of compensatory, protective and energy-sparing responses [5].

\section{Glucose-Lowering Effects of Metformin}

Metformin exerts its glucose-lowering effect primarily by decreasing hepatic glucose production through suppression of gluconeogenesis and enhancing insulin suppression of endogenous glucose production and, to a lesser extent, by reducing intestinal glucose absorption and possibly improving glucose uptake and utilization by peripheral tissues, such as skeletal muscle and adipose tissue [6] (Fig. 1). Further, metformin may also improve glucose metabolism by interacting with the incretin axis through the action of glucagon-like peptide 1 (GLP-1) [7]. Although the mechanisms for metforminmediated increments in GLP-1 levels remain unknown, it has been hypothesized that metformin stimulates GLP-1 secretion directly and/or indirectly and prolongs the half-life of GLP-1, and that metformin may potentiate the glucose-lowering effects of GLP-1 by increasing target tissue sensitivity to GLP-1 [8].

Manuscript submitted November 30, 2018, accepted December 20, 2018

aDepartment of Internal Medicine, National Center for Global Health and Medicine Kohnodai Hospital, Chiba, Japan

${ }^{\mathrm{b}}$ Corresponding Author: Hidekatsu Yanai, Department of Internal Medicine, National Center for Global Health and Medicine Kohnodai Hospital, 1-7-1 Kohnodai, Ichikawa, Chiba 272-8516, Japan.

Email: dyanai@hospk.ncgm.go.jp

doi: https://doi.org/10.14740/jocmr3706

\section{A Significant Influence of Glycemic Variabil- ity (GV) on Microvascular and Macrovascular Complications in Patients With Diabetes}

With the spread of continuous glucose monitoring (CGM), glycemic GV is attracting attention. Emerging evidence suggests that GV contributes to adverse clinical outcome in patients with diabetes [9]. A recent meta-analysis assessing GV has shown associations of $\mathrm{GV}$ with microvascular and macrovascular complications and mortality in type 1 and type 2 diabetes [10]. Proposed mechanisms for GV-induced adverse vascular outcomes include increased oxidative stress and enhanced expression of proteins involved in vascular pathology [11].

\section{A Dose-Dependent Effect of Metformin on GV}

Although various mechanisms have been suggested as metformin-mediated glucose-lowering, it remains unknown which of these mechanisms plays a crucial role at various daily doses of metformin. Our previous [12] and present study using CGM demonstrated that metformin improved GV in a dose-dependent manner (Fig. 2).

\section{The Effect of Combination of Dipeptidyl Pepti- dase 4 (DPP4) Inhibitors With Metformin on GV}

The present study using CGM showed that the combination of DPP4 inhibitor with metformin improved GV (Fig. 2). Effects of combination of metformin with incretin-related drugs (DPP4 inhibitors, GLP-1 analogs) and sodium-glucose cotransporter 2 (SGLT2) inhibitors on GV were shown in Table 1 [13-19]. The combination of metformin with incretin-related drugs significantly improved GV as compared with the combination of metformin with other drugs. The combination of metformin with dapagliflozin (SGLT2 inhibitor) also significantly improved GV as compared with the combination of dapagliflozin with insulin.

\section{Many Participants Had Been Taking Metformin in the Trials of New Anti-Diabetic Drugs That Showed Excellent Cardiovascular Outcomes}

The cardiovascular effect of semaglutide, a GLP-1 analog with 


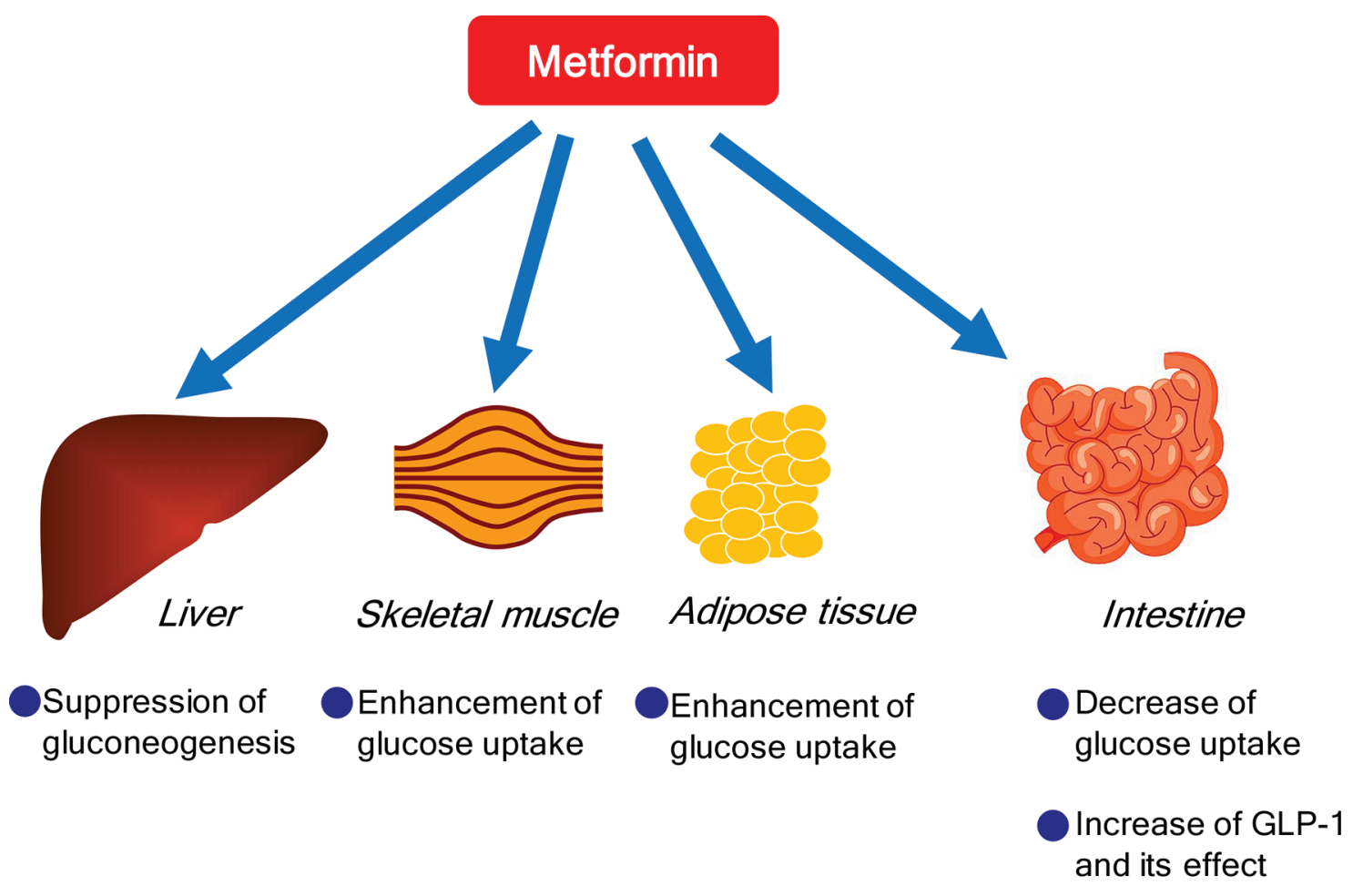

Figure 1. Glucose-lowering effects of metformin.

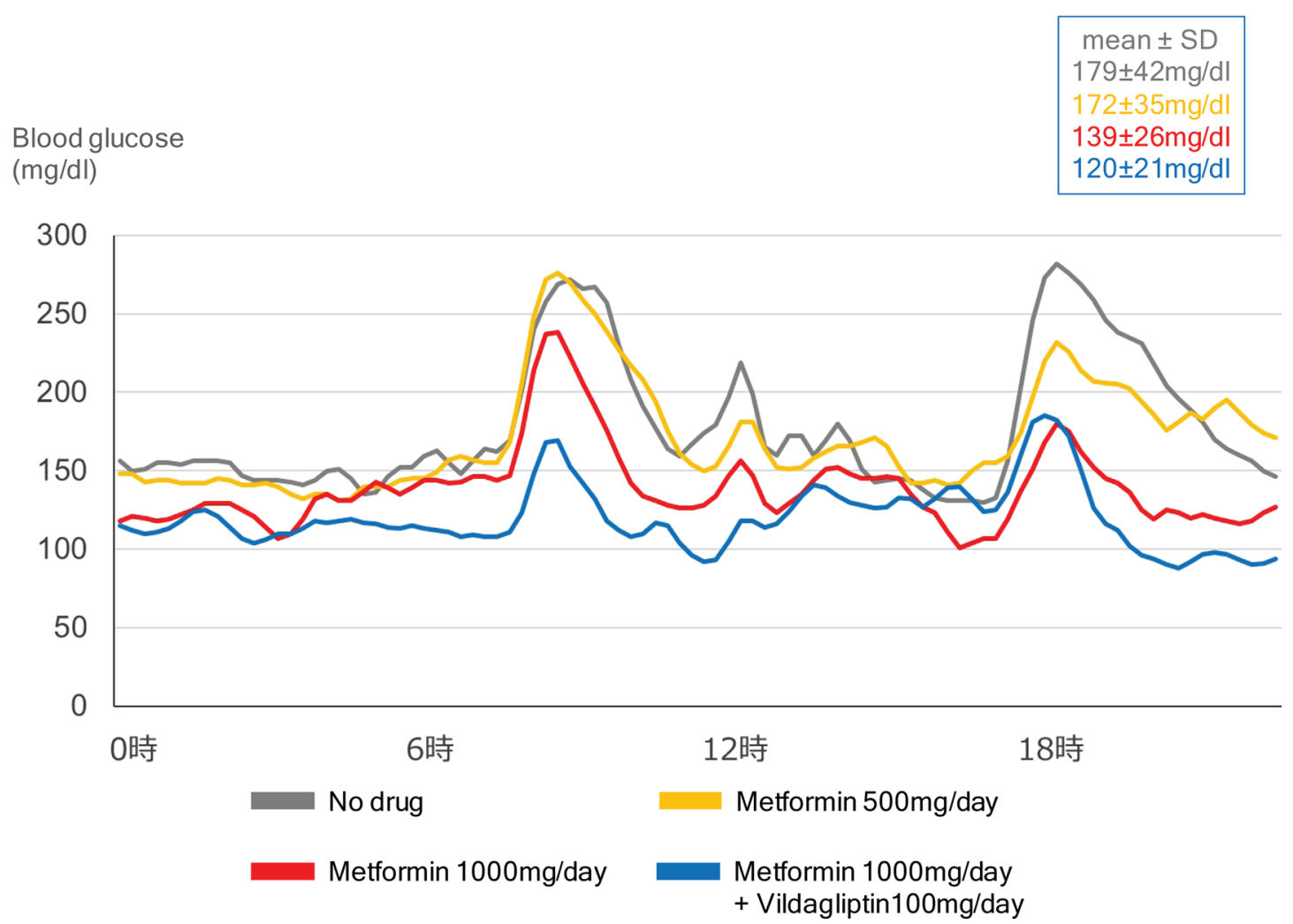

Figure 2. Effects of dose of metformin and combination of metformin with vildagliptin (DPP4 inhibitor) on glycemic variability, in a 55 -year-old type 2 diabetic woman with body mass index of $29.2 \mathrm{~kg} / \mathrm{m}^{2}$. 
Table 1. Effects of Combination of Metformin With Incretin-Related Drugs (DPP4 Inhibitors, GLP-1 Analogs) and SGLT2 Inhibitors on Glycemic Variability

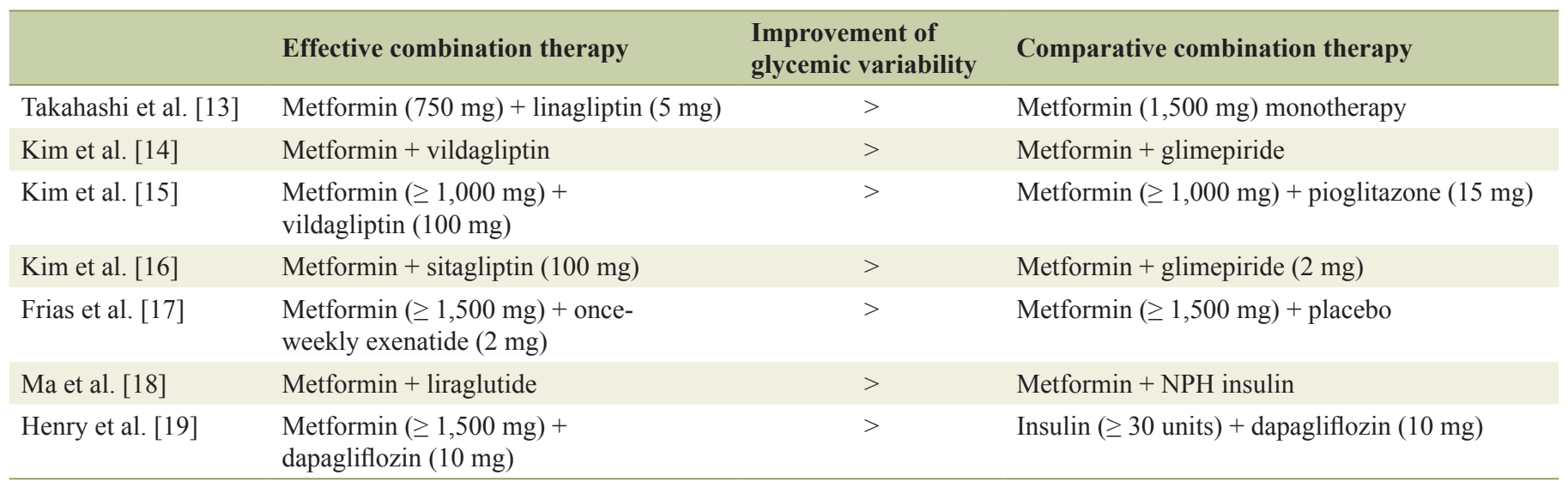

an extended half-life of approximately 1 week, in type 2 diabetes was examined in SUSTAIN-6 [20]. In patients with type 2 diabetes who were at high cardiovascular risk, the rate of cardiovascular death, non-fatal myocardial infarction or nonfatal stroke was significantly lower among patients receiving semaglutide than among those receiving placebo. The cardiovascular effect of liraglutide, a GLP-1 analog, when added to standard care in patients with type 2 diabetes, was evaluated in LEADER Trial [21]. In the time-to-event analysis, the rate of the first occurrence of death from cardiovascular causes, nonfatal myocardial infarction or non-fatal stroke among patients with type 2 diabetes mellitus was lower with liraglutide than with placebo.

The cardiovascular safety profile of dapagliflozin, a
SGLT2 inhibitor in patients with type 2 diabetes, was studied in DECLARE-TIMI 58 [22]. In patients with type 2 diabetes who had or were at risk for atherosclerotic cardiovascular disease, dapagliflozin did not result in a higher or lower rate of major adverse cardiovascular events (MACEs) than placebo but did result in a lower rate of cardiovascular death or hospitalization for heart failure. The effects of empagliflozin, a SGLT2 inhibitor, in addition to standard care, on cardiovascular morbidity and mortality in patients with type 2 diabetes at high cardiovascular risk, were examined in EMPA-REG OUTCOME [23]. Patients with type 2 diabetes at high risk for cardiovascular events who received empagliflozin, as compared with placebo, had a lower rate of the primary composite cardiovascular outcome and of death from any cause. Patients

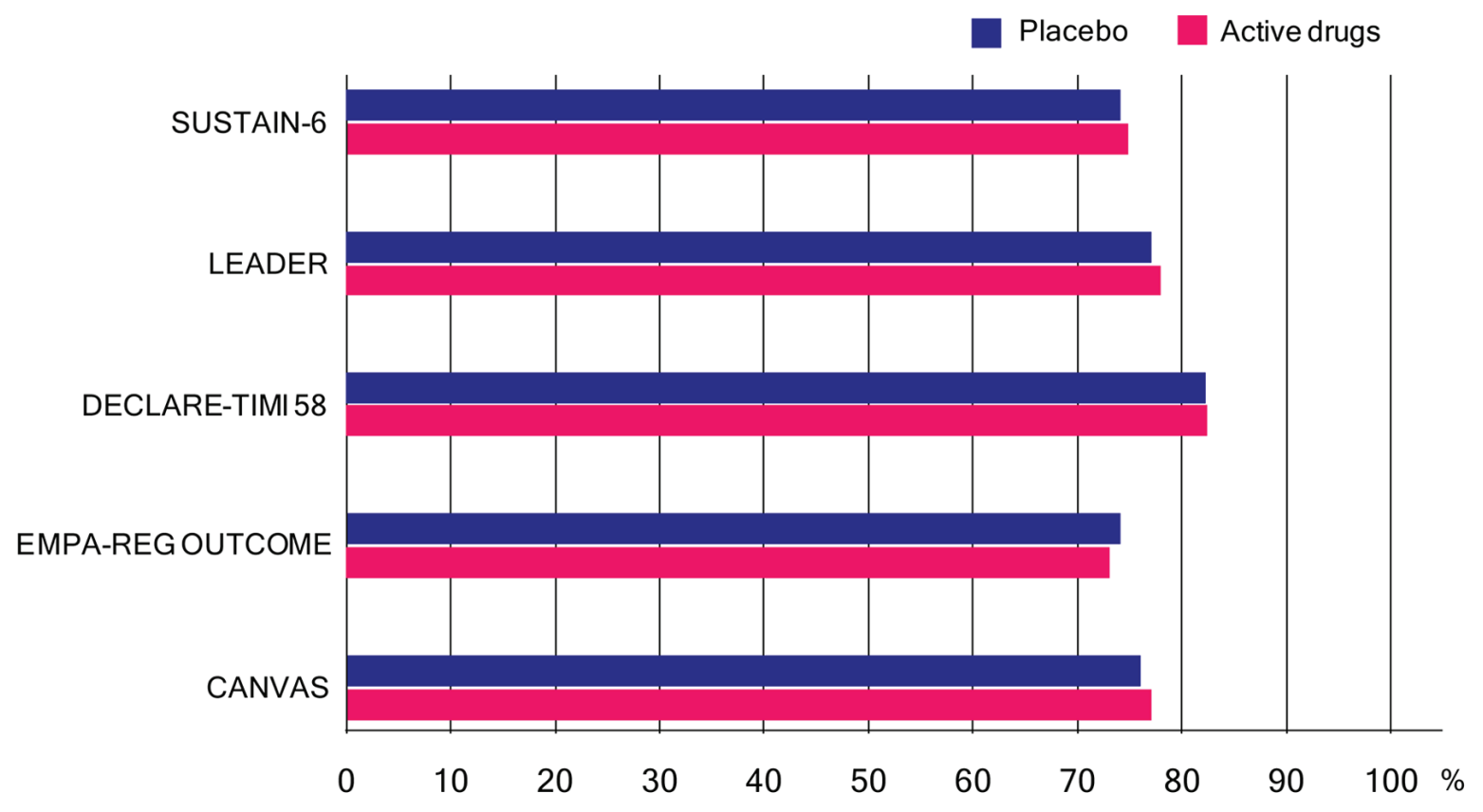

Figure 3. Percentage of patients who had been taking metformin (or biguanides) in SUSTAIN-6, LEADER Trial, DECLARE-TIMI 58, EMPA-REG OUTCOME and CANVAS program. In only SUSTAIN-6, not metformin but biguanides was written in the table which showed baseline characteristics of the patients. 
treated with canagliflozin had a lower risk of cardiovascular events than those who received placebo in CANVAS program [24].

Many patients had been taking metformin in these trials (Fig. 3). As previously mentioned, metformin improves GV which is beneficial for cardiovascular outcome in patients with diabetes. Besides effect on $\mathrm{GV}$, cardio-protective effects of metformin such as improvements in hypertension, endothelial function, myocardial injury, cardiac hypertrophy, diabetic cardiomyopathy and cardiac hypertrophy were reported [2]. The United Kingdom Prospective Diabetic Study (UKPDS) demonstrated that metformin had the advantage of counteracting the cardiovascular complications associated with diabetes [25].

In conclusion, a new class of anti-diabetic drugs may have obtained good results on cardiovascular events thanks to the synergistic effect with metformin or the cardioprotective effect of metformin.

\section{Conflict of Interest}

The authors declare that they have no conflict of interest concerning this article.

\section{References}

1. Davies MJ, D'Alessio DA, Fradkin J, Kernan WN, Mathieu C, Mingrone G, Rossing P, et al. Management of hyperglycemia in type 2 diabetes, 2018. A consensus report by the American Diabetes Association (ADA) and the European Association for the Study of Diabetes (EASD). Diabetes Care. 2018;41(12):2669-2701.

2. Foretz M, Guigas B, Bertrand L, Pollak M, Viollet B. Metformin: from mechanisms of action to therapies. Cell Metab. 2014;20(6):953-966.

3. Foretz M, Hebrard S, Leclerc J, Zarrinpashneh E, Soty M, Mithieux G, Sakamoto K, et al. Metformin inhibits hepatic gluconeogenesis in mice independently of the LKB1/AMPK pathway via a decrease in hepatic energy state. J Clin Invest. 2010;120(7):2355-2369.

4. Stephenne X, Foretz M, Taleux N, van der Zon GC, Sokal E, Hue L, Viollet B, et al. Metformin activates AMP-activated protein kinase in primary human hepatocytes by decreasing cellular energy status. Diabetologia. 2011;54(12):3101-3110.

5. Viollet B, Guigas B, Sanz Garcia N, Leclerc J, Foretz M, Andreelli F. Cellular and molecular mechanisms of metformin: an overview. Clin Sci (Lond). 2012;122(6):253270.

6. Natali A, Ferrannini E. Effects of metformin and thiazolidinediones on suppression of hepatic glucose production and stimulation of glucose uptake in type 2 diabetes: a systematic review. Diabetologia. 2006;49(3):434-441.

7. Maida A, Lamont BJ, Cao X, Drucker DJ. Metformin regulates the incretin receptor axis via a pathway dependent on peroxisome proliferator-activated receptor-alpha in mice. Diabetologia. 2011;54(2):339-349.
8. Bahne E, Hansen M, Bronden A, Sonne DP, Vilsboll T, Knop FK. Involvement of glucagon-like peptide-1 in the glucose-lowering effect of metformin. Diabetes Obes Metab. 2016;18(10):955-961.

9. Ajjan RA. How can we realize the clinical benefits of continuous glucose monitoring? Diabetes Technol Ther. 2017;19(S2):S27-S36.

10. Gorst C, Kwok CS, Aslam S, Buchan I, Kontopantelis E, Myint PK, Heatlie G, et al. Long-term glycemic variability and risk of adverse outcomes: a systematic review and meta-analysis. Diabetes Care. 2015;38(12):2354-2369.

11. Kuricova K, Pacal L, Soupal J, Prazny M, Kankova K. Effect of glucose variability on pathways associated with glucotoxicity in diabetes: Evaluation of a novel in vitro experimental approach. Diabetes Res Clin Pract. 2016;114:1-8.

12. Akiyama T, Hamasaki H, Adachi H, Yanai H. Understanding of dose-response of metformin by using continuous glucose monitoring. J Endocrinol Metab. 2017;7(2):7274.

13. Takahashi H, Nishimura R, Tsujino D, Utsunomiya $\mathrm{K}$. Which is better, high-dose metformin monotherapy or low-dose metformin/linagliptin combination therapy, in improving glycemic variability in type 2 diabetes patients with insufficient glycemic control despite low-dose metformin monotherapy? A randomized, cross-over, continuous glucose monitoring-based pilot study. J Diabetes Investig. 2018.

14. Kim G, Oh S, Jin SM, Hur KY, Kim JH, Lee MK. The efficacy and safety of adding either vildagliptin or glimepiride to ongoing metformin therapy in patients with type 2 diabetes mellitus. Expert Opin Pharmacother. 2017;18(12):1179-1186.

15. Kim NH, Kim DL, Kim KJ, Kim NH, Choi KM, Baik $\mathrm{SH}$, Kim SG. Effects of vildagliptin or pioglitazone on glycemic variability and oxidative stress in patients with type 2 diabetes inadequately controlled with metformin monotherapy: a 16-week, randomised, open label, pilot study. Endocrinol Metab (Seoul). 2017;32(2):241-247.

16. Kim HS, Shin JA, Lee SH, Kim ES, Cho JH, Son HY, Yoon KH. A comparative study of the effects of a dipeptidyl peptidase-IV inhibitor and sulfonylurea on glucose variability in patients with type 2 diabetes with inadequate glycemic control on metformin. Diabetes Technol Ther. 2013;15(10):810-816.

17. Frias JP, Nakhle S, Ruggles JA, Zhuplatov S, Klein E, Zhou R, Strange P. Exenatide once weekly improved 24hour glucose control and reduced glycaemic variability in metformin-treated participants with type 2 diabetes: a randomized, placebo-controlled trial. Diabetes Obes Metab. 2017;19(1):40-48.

18. Ma Z, Chen R, Liu Y, Yu P, Chen L. Effect of liraglutide vs. NPH in combination with metformin on blood glucose fluctuations assessed using continuous glucose monitoring in patients with newly diagnosed type 2 diabetes. Int J Clin Pharmacol Ther. 2015;53(11):933-939.

19. Henry RR, Strange P, Zhou R, Pettus J, Shi L, Zhuplatov SB, Mansfield T, et al. Effects of dapagliflozin on 24hour glycemic control in patients with type 2 diabetes: 
a randomized controlled trial. Diabetes Technol Ther. 2018;20(11):715-724.

20. Marso SP, Bain SC, Consoli A, Eliaschewitz FG, Jodar E, Leiter LA, Lingvay I, et al. Semaglutide and Cardiovascular Outcomes in Patients with Type 2 Diabetes. N Engl J Med. 2016;375(19):1834-1844.

21. Marso SP, Daniels GH, Brown-Frandsen K, Kristensen P, Mann JF, Nauck MA, Nissen SE, et al. Liraglutide and cardiovascular outcomes in type 2 diabetes. N Engl J Med. 2016;375(4):311-322.

22. Wiviott SD, Raz I, Bonaca MP, Mosenzon O, Kato ET, Cahn A, Silverman MG, et al. Dapagliflozin and cardiovascular outcomes in type 2 diabetes. N Engl J Med.
2018.

23. Zinman B, Wanner C, Lachin JM, Fitchett D, Bluhmki E, Hantel S, Mattheus M, et al. Empagliflozin, cardiovascular outcomes, and mortality in type 2 diabetes. N Engl J Med. 2015;373(22):2117-2128.

24. Neal B, Perkovic V, Mahaffey KW, de Zeeuw D, Fulcher G, Erondu N, Shaw W, et al. Canagliflozin and cardiovascular and renal events in type 2 diabetes. N Engl J Med. 2017;377(7):644-657.

25. UK Prospective Diabetes Study (UKPDS) Group. Effect of intensive blood-glucose control with metformin on complications in overweight patients with type 2 diabetes (UKPDS 34). Lancet. 1998;352(9131):854-865. 